\title{
COD and colour removal from molasses spent wash using activated carbon produced from bagasse fly ash of Matahara sugar factory, Oromiya region, Ethiopia
}

\author{
Jemal F Nure ${ }^{1 *}$, Nurelegne T Shibeshi ${ }^{2}$, Seyoum L Asfaw ${ }^{3}$, Wim Audenaert ${ }^{4}$ and Stijn WH Van Hulle ${ }^{4}$ \\ 'Ethiopian Institute of Water Resources, Akaki campus, Addis Ababa University, P.O. Box 150461, Addis Ababa, Ethiopia \\ 2Biological and Chemical Engineering, Addis Ababa Science and Technology University, , P.O Box: 16417, Addis Ababa, Ethiopia \\ ${ }^{3}$ Centre for Environmental Science, Addis Ababa University, P.O. Box, 1176, Addis Ababa, , Ethiopia \\ ${ }^{4}$ Department of Industrial Biological Sciences, Ghent University, Graaf Karel de Goedelaan 5, B-8500, Kortrijk, Belgium
}

ABSTRACT
The aim of this study was to investigate the removal of chemical oxygen demand (COD) and colour from
a melanoidin solution using activated carbon produced from bagasse fly ash (BFA). Melanoidins are
heterogeneous polymers and major contributors to the dark brown colour of molasses spent wash, which is
an extensive cause of environment pollution. The surface area of the BFA was determined as $160.9 \pm 2.8 \mathrm{~m}^{2} / \mathrm{g}$
with $90 \%$ of particle less than $156.8 \mu \mathrm{m}$ in size. Characterization of the BFA by Fourier transform infrared
spectroscopy (FTIR) showed the presence of hydroxyl and carbonyl functional groups, whereas X-ray
diffraction analysis indicated its amorphous nature. Moreover, scanning electron microscopy analysis showed
a heterogeneous and irregular shape of pores. Among the adsorption isotherm models analysed, the Freundlich
model fitted best to the experimental data, indicating a maximum adsorptive capacity of $124.80 \mathrm{mg} / \mathrm{g}$. The
removal of COD and colour from a melanoidin solution with this activated carbon was carried out using an
experimental design taking 4 factors into account. These were adsorbent dose, contact time, pH and initial
COD concentration, with removal of COD and colour as response variables. COD reduction was influenced by
initial COD concentration whereas colour removal was dominated by contact time, which was in line with the
findings of principal component analysis . The maximum COD removal recorded was $61.6 \%$ at the optimum
condition of adsorbent dose of $4 \mathrm{~g}$ in $100 \mathrm{~mL}$, contact time of $4 \mathrm{~h}$, pH 8 and initial COD concentration
$6000 \mathrm{mg} / \mathrm{L}$, whereas the decolourization of melanoidin solution was $64 \%$ at adsorbent dose of $4 \mathrm{~g}$, contact
time $4 \mathrm{~h}$, pH 3 and initial COD concentration $6000 \mathrm{mg} / \mathrm{L}$. Hence, activated BFA is a promising option for
simultaneous removal of COD and colour from molasses spent wash under the stated conditions.
Keywords: adsorption; factorial design; distillery spent wash; melanoidins; optimization;
COD and colour removal

\section{INTRODUCTION}

Fossil fuel depletion and concerns over climate change and energy security have stimulated interest in more sustainable and low-carbon energy production in various countries around the world (Chooyok et al., 2013). Bioenergy is the carbonneutral and renewable energy resource that can be converted into any form of fuel for utilization. Globally, ethanol distillery industries are growing rapidly to satisfy the increasing demand for sustainable and renewable biofuel, particularly bioethanol (David et al., 2015). The estimated global demand for bioethanol in 2020 will rise beyond $1.2 \times 10^{11} \mathrm{~L}$ and molasses make up the largest portion of the feedstock for distillery industries, as indicated by Arimi et al. (2015). However, ethanol distillery industries generate large volumes of high-strength wastewater, termed molasses spent wash. The ever-increasing generation of molasses spent wash results in unwanted residual liquid waste that poses a serious threat to the water quality and soil properties in several regions around the globe (Mohana et al., 2009). The imposition of stringent environmental regulations and environmental demand for bioethanol are driving forces in the treatment of molasses spent wash using different technologies (Kazemi et al., 2015).

For every litre of ethanol production, about $15 \mathrm{~L}$ of molasses spent wash is generated (Yadav et al., 2011). Spent wash is very acidic in nature, highly charged in organic matter, and is considered to be a troublesome and complex industrial wastewater (Mohana et al., 2007). Generally, distillery spent wash is classified as high-strength industrial wastewater and environmentally considered as 'red' category waste, due to its high content of organic matter with very low degradability. For instance, a COD range of $110000-190000 \mathrm{mg} / \mathrm{L}$ ) and BOD range of 50 000-60 $000 \mathrm{mg} / \mathrm{L}$ for molasses spent wash has been reported (Acharya et al., 2008). Another peculiar feature of the spent wash is its colour, which is deep dark brown. The colour of spent wash is mainly due to melanoidins, which account for $2 \%$ of total spent wash by mass (Naik et al., 2010). Colour removal is a challenge for melanoidins containing distillery wastewater.

Melanoidin is the final product of the dehydration and condensation of sugar and amino acids under non-enzymatic

\footnotetext{
To whom all correspondence should be addressed:

前 +25191208 3842; email: fitojemal120@gmail.com

Received 8 August 2016; accepted in revised form 23 June 2017
} 
(Maillard chemical) reactions (Wang et al., 2011). It is a recalcitrant, antioxidant, acidic, nitrogen-containing dark brown polymeric compound (David et al., 2015). The molecular weight of melanoidin is estimated to be between of 5000 and $40000 \mathrm{Da}$, having an empirical formula of $\mathrm{C}_{17-18} \mathrm{H}_{26-27} \mathrm{O}_{10} \mathrm{~N}$ (Krishna Prasad and Srivastava, 2009). Molasses-based ethanol distillery spent wash is the major source of melanoidin wastewater (Yadav et al., 2011).

Discharge of untreated melanoidin-containing spent wash can block sunlight in water bodies, which results in reduced photosynthetic activity and oxygen concentration, which inhibits the survival of aquatic life (Dahiya et al., 2001). Hence, distillery spent wash which contains melanoidins has to be treated prior to discharge into the natural environment to prevent water pollution and ecological impacts, although removal with different treatment methods is challenging. Spent wash colour removal by conventional wastewater treatment is an unsolved issue (Arimi et al., 2014). Moreover, melanoidins have antioxidant and antimicrobial properties that suppress the growth of bacteria, which in turn can result in very low biodegradation (Rufián-Henares and Morales, 2007). Among many treatment methods, ozone treatment technology for distillery spent wash is effective. However, wastewater treatment by ozonation is not always feasible because of the high operational cost and demand for electricity. Adsorption is another physicochemical treatment technology which is frequently used in water and wastewater treatment. It is a powerful and efficient technique in the removal of organic matter and colour from industrial wastewaters (Kushwaha et al., 2010) but the great limitation is the cost. Hence, many studies are looking into the production of low-cost, efficient adsorbents derived from easily available materials such as industrial solid wastes and by-products.

Bagasse fly ash (BFA) is industrial solid waste generated from burning of bagasse in steam boilers to generate electric energy in the sugar industry. In most developing countries, BFA is not commercialized and remains as a waste that causes great problems for environmental disposal. Studies have shown that it is a carbon- and silica-rich industrial waste which is cheap and available in large quantities in many sugar industries (Mall et al., 2005). It has been used as an adsorbent for removal of heavy metals, organic matter and dyes from water and wastewater under different treatment conditions. For instance, for adsorption of acrylonitrile from aqueous solution (100 $\mathrm{mg} / \mathrm{L}$ ) BFA has been used as an adsorbent with surface area of $379.64 \mathrm{~m}^{2} / \mathrm{g}$ and giving $78 \%$ removal efficiency (Kumar et al., 2014). A treatment efficiency of $99.16 \%$ was also achieved for removal of copper ion from aqueous solution at $77.88 \mathrm{mg} / \mathrm{L}$ initial copper concentration (Ghosh and Saha, 2015).

Application of BFA for pulp and paper industry effluent treatment was studied and adsorptive removal efficiencies of $50 \%$ and $55 \%$ for COD and colour, respectively, were reported (Srivastava et al., 2005). In another study, BFA proximate moisture content was recorded as $7.64 \%$, volatile matter $17.37 \%$, ash $26.43 \%$, fixed carbon $48.56 \%$ and bulk density $133.3 \mathrm{~kg} / \mathrm{m}^{3}$ (Srivastava et al., 2006). The low value of fixed carbon (19.20\%) and high ash content (72.60\%) were also reported (Chandra et al., 2007). With respect to BFA adsorbent development, a surface area of $168.83 \mathrm{~m}^{2} / \mathrm{g}$ was developed and its effectiveness tested for removal of malachite green dyes from aqueous solution. Results revealed an adsorption capacity of $9.971 \mathrm{mg} / \mathrm{g}$ (Mall et al., 2005). But adsorption capacity of the BFA is variable due to burning of bagasse in different steam boilers; the variety and composition of the sugarcane used also generates different characteristics for BFA (Srivastava et al., 2005). Generally, activated carbon preparation from BFA has been studied intensively using physical (steam and $\mathrm{CO}_{2}$ ) and chemical $\left(\mathrm{KOH}, \mathrm{H}_{2} \mathrm{O}_{2}, \mathrm{HCl}\right.$, EDTA and $\mathrm{HNO}_{3}$, etc.) processes, but the practical utilization of this resource as an effective treatment option in sugar and ethanol industries for recycling of waste is limited (Purnomo et al., 2012). Moreover, the efficiency of the adsorption technology of activated carbon depends on the nature of the adsorbent, activating agent and activation condition, which generate different surface areas and pore volumes for the interactions between the adsorbate and adsorbent (Gottipati and Mishra, 2010).

Adsorption performance without adsorbent surface modification is low. For instance, untreated BFA vs. that chemically modified with $\mathrm{HCl}$ and $\mathrm{HNO}_{3}$ resulted in adsorption capacities of $19.8,47.6$ and $25.1 \mathrm{mg} / \mathrm{g}$, respectively, when used for removal of Cd (II) from aqueous solution (El-Sherif and Fathy, 2013). Treating biosorbents such as BFA with hydrogen peroxide is known to increase the adsorption capacity nearly threefold(Nagda and Ghole, 2009). Furthermore, hydrogen peroxide can increase the positive valence by electron removal (Chapman, 2003), which is expected to enhance the treatment of negatively-charged (acidic) melanoidin solutions. Hence, activating carbonaceous material using hydrogen peroxide is effective in removing unwanted organic matter on the surface of BFA and the residue of hydrogen peroxide on the adsorbent surface has no significant environmental impact.

Most of the studies conducted so far on distillery spent wash have focused on either colour removal or COD reduction, although both aspects should be studied together for cost effectiveness. Therefore, the main aim of this study was to investigate the optimum conditions for both COD and colour removal from melanoidin solution by batch adsorption on activated BFA. Hence, the experimental design considered 4 factors: $\mathrm{pH}$, adsorbent dose, initial COD concentration and contact time. These factors were studied using a full factorial experimental design. The main advantages of using this approach are the low cost, minimum number of experiments, reduced treatment time and possibility to investigate interaction effects.The physicochemical characterization and the properties of the adsorbent produced are also investigated and reported.

\section{METHODS}

\section{Adsorbent development}

Bagasse fly ash was collected from the dumping site of the Metahara sugar factory in the regional state of Oromiya (Ethiopia). It was taken to the laboratory and sun-dried for 2 days. Part of the dried BFA was soaked in hydrogen peroxide ( $30 \%$ by concentration) at $60^{\circ} \mathrm{C}$ for $24 \mathrm{~h}$ to remove the organic matter for surface modification. Then it was repeatedly washed with de-ionized water until all hydrogen peroxide on the surface was removed. This modified BFA was placed into an oven at $100^{\circ} \mathrm{C}$ until it was dried completely. Finally, it was powdered, sieved and stored in a vacuum desiccator until use (Gupta et al., 2002). 


\section{Adsorbent characterization}

\section{Proximate analysis}

Proximate analysis of BFAwas as per standard method of ASTM (Milne et al., 1990). The ash content, moisture and volatile matter of the adsorbent were calculated directly, whereas the amount of fixed carbon was calculated as the difference between the initail total mass adsorbent and the sum of the mass of volatile ash and fixed carbon (Nwabanne and Igbokwe, 2012).

\section{Particle size determination}

Particle size distribution was measured based on the principle of laser diffraction, which is capable of measuring particle sizes between $20 \mathrm{~nm}$ and $2000 \mu \mathrm{m}$ according to Malvern Master Sizer Manual (Mastersizer 2000 User Manual 2007).

\section{Fourier transform infrared spectroscopy (FTIR)}

A small amount of the adsorbent sample was mixed with dry $\mathrm{KBr}$ in the ratio of 2:200 and ground. The well-mixed sample was placed on a $\mathrm{ZnSe}$ crystal and pressure was applied. Then the sample was scanned over a wavelength of $600-4000 \mathrm{~cm}^{-1}$ by an attenuated total reflection FT-IR (ThermoNicolet 5700). The spectrum of FTIR was obtained at the scanning rate of 32 times/min with a $4 \mathrm{~cm}^{-1}$ resolution (Dolphen and Thiravetyan, 2011).

\section{Elemental analysis}

For CHNS elemental analyses, $2 \mathrm{mg}$ of the adsorbent sample was mixed with $5 \mathrm{mg}$ of catalyst $\left(\mathrm{VO}_{5}\right)$ and placed into a tin cup, whereas for oxygen analysis, $2 \mathrm{mg}$ of sample was placed into a silver cup without $\mathrm{VO}_{5}$. Then the sample was burned in a column at different temperatures according to the standard methods of the instrument (Thermo Scientific FLASH 2000 CHNS/O elemental analyser). The degassed samples were separated and the chromatograms were created. Finally, the mass percentage of each element was calculated (Tezcan et al., 2015).

\section{Determination of specific surface area}

A sample of $0.1 \mathrm{~g}$ of BFA was mounted on the port of a TriStar II (TriStar II Series, Micromeritics Instrument Corporation) and degassed overnight at $120^{\circ} \mathrm{C}$ under vacuum. Then it was placed into liquid nitrogen at $-196.15^{\circ} \mathrm{C}$ and the increased uptake of $\mathrm{N}_{2}$ was measured. The surface area of the adsorbent was calculated using the BET method in the range of $\left(\mathrm{p} / \mathrm{p}_{0}\right)$ of 0.05-0.20 (Tezcan et al., 2015).

\section{Scanning electron microscope (SEM) analysis}

A surface morphology of adsorbent (BFA) was determined using SEM and SEI resolution $1.0 \mathrm{~nm}$ guaranteed at $15 \mathrm{kV}$ (JEOL JSM-7600F FEG-SEM, JEOL, USA). The sample was applied on carbon tape, and measured at a working distance of $8 \mathrm{~mm}$.The sample preparation and analysis were done as per standard operating procedures of JEOL JSM 7600F SEM which was operated at $15 \mathrm{kV}$ and a current of $10 \mathrm{~A}$ under $1000 \mathrm{X}$ magnifications (Hegazy et al., 2014).

\section{X-ray diffraction (XRD) analysis}

X-ray powder diffraction (XRD) was used for phase identification of the crystalline nature of BFA. XRD analysis of the BFA sample was conducted using an ARL X'TRA powder diffractometer instrument (Thermo Scientific ARL X'TRA Powder Diffractometer, Massachusetts, USA). The x-ray diffractograms were taken using Cuka radiation at a scanning rate of $1 \%$ min in the range $5-60^{\circ} 2 \theta$ at continuous mode of measuring. The XRD diffractometer was switched on at initialization power $15 \mathrm{kV}$ and $5 \mathrm{~mA}$; and the wavelength of the analysis was fixed at $1.541 \mathrm{~nm}$.

\section{Preparation of melanoidin solution}

Synthetic melanoidins were prepared by mixing $4.5 \mathrm{~g}$ of glucose (G8270 D-(+), Sigma-Aldrich), $1.88 \mathrm{~g}$ of glycine (G7126, Sigma-Aldrich) and $0.42 \mathrm{~g}$ of sodium bicarbonate in $100 \mathrm{~mL}$ of distilled water which was heated for $7 \mathrm{~h}$ at $94.85^{\circ} \mathrm{C}$ until dried. Then $100 \mathrm{~mL}$ of distilled water was added to form a melanoidin solution (Bernardo et al., 1997). Diluted solutions of melanoidin were then prepared according to the initial concentrations required for the optimization process and the $\mathrm{pH}$ was adjusted using $0.1 \mathrm{M} \mathrm{NaOH}$ and $0.1 \mathrm{M} \mathrm{HCl}$ solutions.

\section{Adsorption equilibrium isotherms}

Equilibrium isotherm experiments were undertaken in a batch adsorption system under optimum conditions of initial COD concentration $6000 \mathrm{mg} / \mathrm{L}, \mathrm{pH} 8$ and contact time $4 \mathrm{~h}$, but the adsorbent dose was changed from 0.5 to $5 \mathrm{~g}$ in 100 $\mathrm{mL}$. Observed values were compared to different adsorption isotherms. The fundamental principle of adsorption isotherms is a set of assumptions that are related to the heterogeneity or homogeneity of the solid surface and the possibility of interaction between the adsorbate species and adsorbents. In this work, Freundlich and Langmuir's isothermal models were used, which are the most commonly applied models in water and wastewater treatment. The amount of adsorbate attached on the surface of the adsorbent is expressed as follows:

$$
q_{e}=\left(\frac{C_{0}-C_{e}}{m}\right) V
$$

where: $q_{e}$ is adsorbate uptake at equilibrium $(\mathrm{mg} / \mathrm{g}), C_{0}$ and $C_{e}$ are the initial and equilibrium concentrations $(\mathrm{mg} / \mathrm{L})$, respectively; $V$ is the volume of adsorbate solution $(\mathrm{L})$ and $\mathrm{m}$ is the sorbent mass (g) (Kumar et al. 2014).

The Langmuir equation was developed from the adsorbate equilibrium between the liquid and adsorbent surface (Lata et al., 2008). The general equation is as follows:

$$
q_{e}=\frac{Q_{0} C_{e} K_{l}}{1+C_{e} K_{l}}
$$

The linear form of the equation is:

$$
\frac{1}{q_{e}}=\frac{1}{Q_{0}}+\frac{1}{Q_{0} C_{e} K_{l}}
$$

where: $C_{e}$ is the equilibrium concentration $(\mathrm{mg} / \mathrm{L}), Q_{0}$ maximum the adsorption capacity $(\mathrm{mg} / \mathrm{g}), q_{\mathrm{e}}$ absorptivity capacity $(\mathrm{mg} / \mathrm{g})$, and $\mathrm{K}_{1}$ the Langmuir isotherm constant $(\mathrm{L} / \mathrm{mg})$. In this equation, the graph of $\frac{1}{q_{e}}$ vs $\frac{1}{C_{e}}$ was plotted; $Q_{0}$ and $K_{1}$ were constants, which can be calculated from the intercept and slope of the equation, respectively. 
The Freundlich isothermal model is based on the principle of heterogeneous surface of adsorbents (Simaratanamongkol and Thiravetyan 2010). The equation is as follows:

$$
q_{e}=k_{f} C_{e}^{1 / m}
$$

The linear form of the equation is:

$$
\log q e=\log k+\frac{1}{n} \log c e
$$

where: $q_{e}(\mathrm{mg} / \mathrm{g})$ is the adsorbed amount of the adsorbate per unit mass of the adsorbent, $C_{e}(\mathrm{mg} / \mathrm{L})$ is the equilibrium concentration in $\mathrm{mg} / \mathrm{L}, K_{f}\left((\mathrm{mg} / \mathrm{g})(\mathrm{L} / \mathrm{mg})^{1 / n}\right)$ is the Freundlich constant which is associated with the adsorbent capacity of the adsorption and $n$ (unitless) is the Freundlich constant which is directly related to favourability of the adsorption process.

\section{Optimization of batch adsorption}

Batch tests were carried out by adding $100 \mathrm{~mL}$ of adsorbate (melanoidin) solution to $250 \mathrm{~mL}$ conical flasks using 16 different combinations of the upper and lower values of the factors. Flasks were agitated at $160 \mathrm{r} / \mathrm{min}$ using an orbital shaker. The solution was then centrifuged at $3500 \mathrm{r} / \mathrm{min}$ for $30 \mathrm{~min}$. Finally, the solution was filtered using Whatman filter paper 42 (pore size $2.5 \mu \mathrm{m}$ ). The filtrate was collected for further COD and colour analysis as per standard methods (APHA, 1998). In the first set of experiments, a screening of the most important factors, i.e., initial COD concentration, adsorbent dose, contact time and $\mathrm{pH}$, was performed. The design of this experiment was a $2^{4}$ full factorial design with 16 runs (Table 1), which was conducted at room temperature. Colour removal and COD reduction of melanoidin solutions were chosen as response variables. The experiments were performed in a random manner with the lower and higher values corresponding to $(-1)$ and $(+1)$, respectively. The levels of each factor were selected based on the literature values (Maurice, 2012).

\begin{tabular}{|l|c|c|c|}
\hline \multicolumn{4}{|c|}{ TABLE 1} \\
\hline Sactors & Code & Low(-) & High(+) \\
\hline Concentration $(\mathrm{mg} / \mathrm{L})$ & $X_{1}$ & 1000 & 6000 \\
\hline Adsorbent dose $(\mathrm{g}$ in $100 \mathrm{~mL})$ & $X_{2}$ & 1 & 4 \\
\hline $\mathrm{pH}$ & $X_{3}$ & 3 & 8 \\
\hline Contact time $(\mathrm{h})$ & $X_{4}$ & 1 & 4 \\
\hline
\end{tabular}

\section{COD and colour analysis}

For colour analysis, the absorbance of the filtrate sample was determined at the characteristic wavelength of $475 \mathrm{~nm}$ using a double beam UV-Vis spectrophotometer (Agilent technology, Cary 100 UV-Visible Spectrophotometer) (Krishna Prasad and Srivastava, 2009). The colour removal percentage was calculated based on the value of initial melanoidin solution and its value after the adsorption treatment, whereas the COD reduction measurement was made using the initial COD concentration and its value after passing through the treatment by open reflex method (APHA, 1998).

\section{Statistical analysis}

The experimental results were analysed by linear regression. Colour removal and COD reduction were considered as response variables $(Y)$ and the removal efficiency of response variables was given by the following equation

$$
\begin{aligned}
& Y_{\mathrm{COD} / \text { Colour }} \\
& =b_{0}+b_{1} X_{1}+b_{2} X_{2}+b_{3} X_{3}+b_{4} X_{4}+b_{5} X_{1} X_{2}+b_{6} X_{1} X_{3} \\
& +b_{7} X_{1} X_{4}+b_{8} X_{2} X_{3}+b_{9} X_{2} X_{4}+b_{10} X_{3} X_{4}+b_{11} X_{1} X_{2} X_{3} \\
& +b_{12} X_{1} X_{2} X_{3}+b_{13} X_{1} X_{3} X_{4}+b_{14} X_{2} X_{3} X_{4}+b_{15} X_{1} X_{2} X_{3} X_{4}
\end{aligned}
$$

where: $Y_{\mathrm{COD}}$ and $Y_{\text {colour }}$ are the response variables for COD and colour, respectively, $b_{o}$ is the mean of the measurements and $b_{i}$ is the regression coefficient of the main and interaction effects. The significance of the regression model was checked using analysis of variance (ANOVA) at 95\% confidence level. The coefficient of determination, $R^{2}$, and adjusted coefficient of determination were used to determine the fit between the model and experimental data. Generally, the model equation was used to identify the influence of the experimental factors and their interaction on colour and COD removal. For statistical analysis with principal component analysis (PCA), the software program SPSS version 23 was used (www.ibm.com). PCA was used to select the most discriminating parameters and to investigate the overall variation of the data (Van Hulle and Ciocci, 2015). PCA was also used as a pattern recognition method aimed at reducing a large number of variables to a smaller number of representative variables (principal components) (Brereton, 2003). Varimax normalised rotation of principal components was carried out in order to reduce the contribution of variables with minor significance and increase the interpretability of the components. In total, 6 factors (COD removal, colour removal, initial COD concentration, adsorbent dose, contact time and $\mathrm{pH}$ ) were considered. Sixteen batch adsorption experiments were used for this PCA. This ensured that the ratio of the number of experiments to number of factors was relatively low (2.66) compared to a common ratio of 5/1. The Kaiser-MeyerOlkim criterion for sampling adequacy (KMO) and the Bartlett test were used to verify that correlations between items were sufficiently large for PCA (Hair et al. 1998). The KMO value was $0.4(<0.5)$, indicating that the correlations between the variables were relatively low for application of PCA. On the other hand, the Barlett's test of sphericity $(\mathrm{p}=0.05)$ indicated that the correlations between factors were sufficiently high for PCA.

\section{RESULTS AND DISCUSSION}

\section{Elemental and proximate analyses}

Elemental analyses of BFA were carried out before and after the treatment with melanoidin-containing wastewater (Table 2). The carbon content of BFA was high ( $60 \%$ by mass) for locally prepared activated carbon but smaller than commercial activated carbon. However, the compositions of hydrogen, nitrogen and sulphur were low and comparable with the values of commercially activated carbon (Alothman et al., 2011). This indicated that BFA is a carbon-rich substance and 


\begin{tabular}{|l|c|c|}
\hline \multicolumn{3}{|c|}{ TABLE 2 } \\
Elemental analyses of BFA before and after treatment \\
\hline Element & BFA before treatment \% & BFA after treatment \% \\
\hline Carbon & 60.04 & 59.03 \\
\hline Hydrogen & 0.62 & 0.71 \\
\hline Nitrogen & 0.28 & 0.34 \\
\hline Oxygen & 6.77 & 14.54 \\
\hline Sulphur & 0.00 & 0.00 \\
\hline Others & 32.29 & 25.38 \\
\hline
\end{tabular}

${ }^{*}$ The result was calculated by difference (percentage by mass)

good precursor for activated carbon. There was an observable change in oxygen percentages before and after the treatment. The raised oxygen might be attributed to the contribution of pollutants from wastewater. Moreover, the study results also showed that $32.29 \%$ of BFA composition by mass was made up of other elements.

Proximate analysis is used to identify the amount of fixed carbon and non-carbon sources in the adsorbent. The ash content indicates the amount of inorganic substance that remains after the sample was burned off at high temperature whereas the amount of fixed carbon is the non-volatile carbon source of the adsorbent. The proximate analysis of BFA was given as a percentage by weight (Table 3 ). These include moisture content $(7.64 \%)$, ash (26.43\%) and volatile substances $(17.23 \%)$, which are in good agreement with the literature (Mall et al., 2005). However, the amount of fixed carbon (42.2\%) was higher than many adsorbents but still smaller than the commercial activated carbon (Hesas et al., 2013). This result indicates that BFA is a good precursor for adsorbent development and helpful in water and wastewater purification.

TABLE 3

Proximate analyses of BFA before and after treatment

\begin{tabular}{|l|c|}
\hline Proximate analysis & Mass in \% \\
\hline Moisture & 5.0 \\
\hline Volatile matter & 16.8 \\
\hline Ash content & 36.0 \\
\hline Fixed carbon & 42.2 \\
\hline
\end{tabular}

${ }^{*}$ The result was calculated by difference (percentage by mass)

\section{Surface area and particle size determination}

Surface area of BFA was measured by adsorption-desorption of nitrogen gas at constant temperature. The amount of nitrogen gas adsorbed is proportional to the surface area of the adsorbent. BFA surface area analysis was carried out before and after the treatment with the melanoidin solution. The observed data were found to be a good fit with the BET model $\left(R^{2}=0.99\right)$. The experimental results for surface area were $160.9 \pm 2.8 \mathrm{~m}^{2} / \mathrm{g}$ and $72.8 \pm 1.0 \mathrm{~m}^{2} / \mathrm{g}$ before and after treatment with melanoidin solution. This showed that, of the total surface area, only $55 \%$ was occupied by the adsorbates as the result of treatment with the melanoidin solution. This observed value of BET surface area of BFA was average and comparable with literature values of $168.83 \mathrm{~m}^{2} / \mathrm{g}$ and $51 \mathrm{~m}^{2} / \mathrm{g}$ reported by Mall et al. (2005) and Deokar et al. (2016), respectively. Adsorbent particle size is another important factor that plays a significant role in the adsorption process. According to the standard derived diameter of spherical particles, $10 \%$ of the adsorbent sample
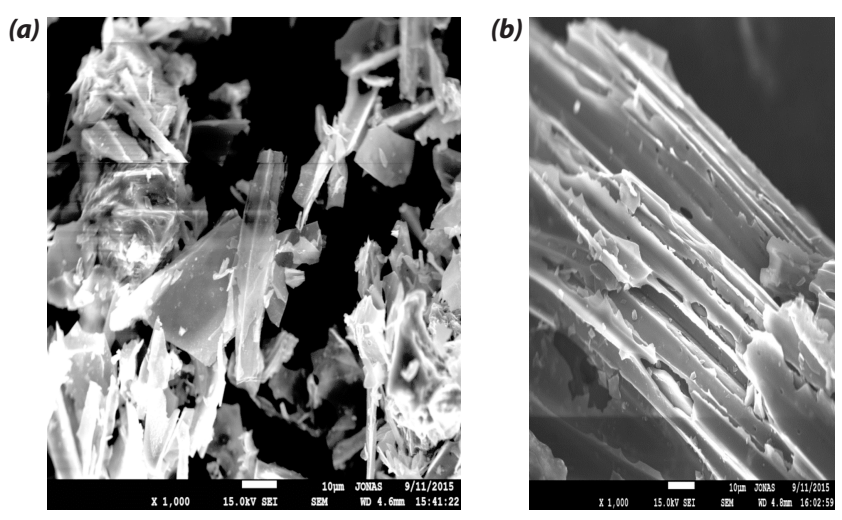

Figure 1

SEM images of BFA before adsorption treatment (a) and after treatment (b) $(x 1000)$

was smaller than $9.5 \mu \mathrm{m}$ in diameter and $50 \%$ of the sample was less than $36.7 \mu \mathrm{m}$. The majority (90\%) of adsorbent particle sizes were less than $156.8 \mu \mathrm{m}$; average particle size was $61.1 \mu \mathrm{m}$. These fine adsorbent particles developed more surface area, enabling fast diffusion of adsorbate to activated sites resulting in faster adsorption kinetics (Madu and Lajide, 2013)

\section{SEM analyses}

SEM analysis of BFA was performed before and after treatment with melanoidin wastewater (Fig. 1). Shape and the pore size on the surface of BFA were not uniform but heterogeneous and irregular in shape. In particular, the larger-sized pores were rough with a lot of cracks which indicated binding sites for adsorbates of different sizes. This was a good indicator of the development of surface porosity and the readiness of the adsorbent to interact with adsorbates, but the chemical nature of the BFA surface is another important factor to be considered. The BFA surface was magnified 1000 times, indicating different pores with the potential to accumulate adsorbate of various sizes and shapes. Moreover, surface porosity was clearly diminished after treatment with melanoidin solution, which in turn proved the attachment of pollutants on the surface of the adsorbent.

\section{Fourier transform infrared spectrophotometry (FTIR) analysis}

FTIR analysis of the BFA sample revealed only two clearly observable peaks. The first broad and long peak was obtained at $3255 \mathrm{~cm}^{-1}$, in the range of $3570-3200 \mathrm{~cm}^{-1}$. This broad peak represents a hydroxyl group in which the hydrogen bond exists in the stretched form. Additionally, an FTIR library search indicated the primary aliphatic alcohol group. The alcohol functional group can be found at $3650-3200 \mathrm{~cm}^{-1}$ which was a long and broad peak. This might be attributed to surface oxidation of BFA by hydrogen peroxide. The other peak was found at around $1700 \mathrm{~cm}^{-1}$, which was associated with $\mathrm{C}=\mathrm{O}$ bond in the range of $1650-1800 \mathrm{~cm}^{-1}$. This group consists of unsaturated aldehydes, ketones, esters and carboxyl functional groups. It gives the hint that hydrogen peroxide led to the surface oxidation and produced the oxygen-bearing functional groups. The chemical activation process for the adsorbent can also break the bond of many functional groups and eliminate volatile and light substrates from the adsorbent surface. 


\section{X-ray diffraction (XRD) analysis}

$\mathrm{X}$-ray diffraction analysis of BFA was conducted at $2 \theta$ in the range $5-60^{\circ}$, which indicated the amorphous nature of the BFA sample with low content of inorganic constituents. There was no significant change in the spectral pattern of the XRD of BFA before and after treatment with melanoidin solution but insignificant peaks were observed which were not clearly identified.

\section{Adsorption isotherms}

Analysis of experimental data using different isothermal models provides fundamental knowledge of the adsorption process and adsorption capacities. The equilibrium data were analysed with the Langmuir and Freundlich models, which are the most well-known models (Gupta et al., 2003). Langmuir's model is based on the principal assumption that the attachment of the adsorbate is only possible if the adsorbent sites are not saturated by monolayer. It is also assumed that all of the vacant sites on the surface of the adsorbent are equivalently sized, similar in shape and uniformly distributed, offering the opportunity of interaction with adsorbates having the same binding energy. In this analysis, the Langmuir model didn't fit the experimental data, which indicates that the adsorption process was not homogenous. Accordingly, negative values of $K$ and $Q_{o}$ were obtained (Igwe and Abia, 2007). The graph forthe Freundlich model is shown in Fig. 2. $K_{f}$ and $n$ were calculated from the intercept and slope of the linearized form of the equation, respectively.

The calculated value of $K_{f}$ was $2.8 \times 10^{-4}\left(\mathrm{mg}^{1.66} \mathrm{~g}^{-1} \cdot \mathrm{L}^{-0.66}\right)$ and $n$ was 0.66 , which are small but are attributed to a cooperative type of adsorption. As stated by Dada et al. (2012) the value of $n=1$ indicates that the equilibrium distribution between the solid and liquid phase is independent of the concentration, whereas $1 / n>1$ or $1 / n<1$ shows cooperative

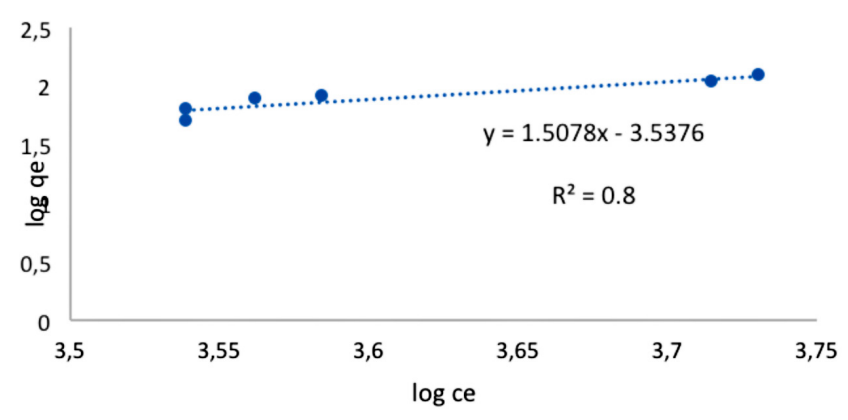

Figure 2

Freundlich plot for COD removal using activated BFA

and normal adsorption, respectively. The $R^{2}$ value for the Freundlich model was 0.85 and for the Langmuir model was 0.77 , indicating that the Freundlich model better describes the experimental data, indicating multilayer adsorption.

\section{COD and colour analyses}

The factorial matrix, experimental results and corresponding predicted modeling values are shown in Table 4. Removal of COD and colour were carried out simultaneously by adsorption. Optimum conditions for maximum COD removal (61.6\%) were adsorbent dose $4 \mathrm{~g}, \mathrm{pH} 8$, initial COD concentration $6000 \mathrm{mg} / \mathrm{L}$, and contact time $4 \mathrm{~h}$, whereas the optimum conditions for maximum melanoidin decolourization (64.0\%) were adsorbent dose $4 \mathrm{~g}, \mathrm{pH} 3$, initial COD concentration $6000 \mathrm{~g} / \mathrm{L}$, and contact time $4 \mathrm{~h}$. It is practically impossible to maintain the same treatment at different optimum conditions. The single optimum point for the maximum removal of both COD (61.6\%) and colour (58.3\%) was found at optimum conditions for COD removal.

\begin{tabular}{|c|c|c|c|c|c|c|c|c|}
\hline \multicolumn{9}{|c|}{$\begin{array}{l}\text { TABLE } 4 \\
\text { Experimental adsorption matrix for COD and colour removal percentage }\end{array}$} \\
\hline \multirow[t]{2}{*}{$\#$} & \multicolumn{4}{|c|}{ Factors } & \multicolumn{2}{|c|}{ COD values } & \multicolumn{2}{|c|}{ Colour removal value } \\
\hline & $X_{1}$ & $x_{2}$ & $X_{3}$ & $x_{4}$ & Observed & Predicted & Observed & Predicted \\
\hline 1 & 1 & 1 & 1 & 1 & 61.6 & 56.1 & 58.3 & 50.9 \\
\hline 2 & -1 & 1 & 1 & 1 & 23.2 & 20.2 & 10.4 & 19.9 \\
\hline 3 & 1 & -1 & 1 & 1 & 36.0 & 31.3 & 63.4 & 64.9 \\
\hline 4 & -1 & -1 & 1 & 1 & 25.0 & 22.6 & 19.8 & 33.9 \\
\hline 5 & 1 & 1 & -1 & 1 & 52.4 & 49.5 & 64.0 & 51.3 \\
\hline 6 & -1 & 1 & -1 & 1 & 14.0 & $\begin{array}{l}13.7 \\
\end{array}$ & 61.4 & 48.2 \\
\hline 7 & 1 & -1 & -1 & 1 & 19.7 & 24.7 & 59.1 & 65.2 \\
\hline 8 & -1 & -1 & -1 & 1 & 23.2 & 16.1 & 60.0 & 62.1 \\
\hline 9 & 1 & 1 & 1 & -1 & 52.4 & 49.5 & 54.7 & 55.8 \\
\hline 10 & -1 & 1 & 1 & -1 & 10.3 & 13.7 & 25.6 & 24.7 \\
\hline 11 & 1 & -1 & 1 & -1 & 27.2 & 24.7 & 19.3 & 41.8 \\
\hline 12 & -1 & -1 & 1 & -1 & 8.8 & 16.1 & 15.8 & 10.8 \\
\hline 13 & 1 & 1 & -1 & -1 & 44.8 & 56.1 & 38.0 & 27.5 \\
\hline 14 & -1 & 1 & -1 & -1 & 20.3 & 20.2 & 38.1 & 24.4 \\
\hline 15 & 1 & -1 & -1 & -1 & 29.2 & 31.3 & 14.2 & 13.5 \\
\hline 16 & -1 & -1 & -1 & -1 & 20.3 & 22.6 & 3.4 & 10.5 \\
\hline
\end{tabular}




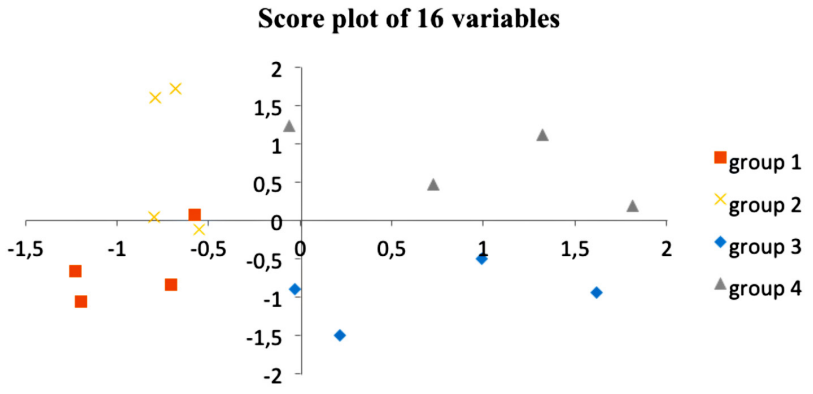

Figure 3

Categorical variables in 4 groups under PCA1 and PCA2

\section{Correlation analysis}

During the adsorption process, the relation between adsorption variables was determined using correlation analysis (Table 5). Two- and single-tailed analyses were carried out. Correlation between the variables was generally weak $(r<0.50)$. For some independent variables $r$ approached zero. Strong correlation was observed only between initial COD concentration and COD removal, for which the $r=0.73$, followed by the correlation between the colour removal and contact time for which $r=0.55$. During single-tailed correlation analyses, all variables had values of $r<0.50$, which shows weak and positive relations (Table 5).

\section{Principal component analysis (PCA)}

In this analysis, PCA was used to identify the major factors that affected colour and COD removal from wastewater, which was revealed by rotated component matrix. The results of the PCA are shown in Table 6. Initial COD concentration and contact time were the main dominant factors for colour and COD removal, respectively. Taking into account the calculated eigenvalues, it was decided to use the first two principal components in this data analysis. The relation of each variable is clearly indicated in Table $6.59 .09 \%$ of the total variance was explained by the first and second principal components. Specifically, the first principal component describes $38.41 \%$ of total variance and the main contributors were initial COD concentration (0.85), followed by adsorbent dose (0.41). However, the contributions of other variables were low $(<0.50)$.
TABLE 6

Rotated component matrix of adsorption factors

\begin{tabular}{|l|c|c|}
\hline \multirow{2}{*}{ Factors } & \multicolumn{2}{|c|}{ Component } \\
\cline { 2 - 3 } & $\mathbf{1}$ & $\mathbf{2}$ \\
\hline COD removal & 0.94 & 0.02 \\
\hline Colour removal & 0.56 & 0.72 \\
\hline Initial COD concentration & 0.85 & -0.10 \\
\hline Adsorbent dose & 0.41 & 0.09 \\
\hline $\mathrm{pH}$ & 0.14 & -0.48 \\
\hline Contact time & 0.12 & 0.81 \\
\hline
\end{tabular}

The second principal component accounts for $20.67 \%$ of the total variance; contact time $(0.81)$ and $\mathrm{pH}$ were the main sources for total variance.

In the PCA analysis only initial COD concentration and contact time were identified as the most influential factors. After the screening, the two factors were analysed and each variable's value was calculated (Fig. 3). The variables were categorized into 4 groups based on the PCA1 and PCA2 results. The results show that the higher the initial COD concentration, the more effective the removal of COD and that the removal efficiency for colour increased with greater contact time and vice versa. Furthermore, these groups were clearly separated by the first and second principal components but the other principal components attribution to variation is limited.

\section{Optimization for COD and colour removal}

It was observed that the regression model terms of 3-way and 4 -way interactions were insignificant at $95 \%$ and neglected in the analysis. According to the regression model output, statistically insignificant terms in the model had no significant impact on COD or colour removal. Hence, only the main effects and the two-way interactions were used to determine the influence on the treatment. The regression analyses were carried out at 95\% confidence level and the results are shown in Tables 7 and 8 . The regression coefficient of determination $\left(R^{2}\right)$ was used to identify the degree of variability in response that was explained by the linear regression model whereas the $p$ values were used to judge whether the results of the main and interaction effects were statistically significant or not. Hence, the results in Table 7 show that the model terms corresponding

\begin{tabular}{|c|c|c|c|c|c|c|c|}
\hline \multicolumn{8}{|c|}{$\begin{array}{c}\text { TABLE } 5 \\
\text { Correlation matrix for dependent and independent variables }\end{array}$} \\
\hline & & COD removal & Colour removal & Initial COD concentration & dose & $\mathrm{pH}$ & Contact time \\
\hline \multirow[t]{6}{*}{ Correlation } & COD removal & 1 & 0.46 & 0.73 & 0.37 & 0.08 & 0.17 \\
\hline & Colour removal & 0.46 & 1 & 0.40 & 0.28 & -0.21 & 0.55 \\
\hline & Concentration & 0.73 & 0.40 & 1 & 0 & 0 & 0 \\
\hline & Dose & 0.37 & 0.28 & 0 & 1 & 0 & 0 \\
\hline & $\mathrm{pH}$ & 0.08 & -0.21 & 0 & 0 & 1 & 0 \\
\hline & Time & 0.17 & 0.55 & 0 & 0 & 0 & 1 \\
\hline \multirow[t]{6}{*}{ Sig.(1-tailed) } & COD removal & & 0.04 & 0.00 & 0.08 & 0.38 & 0.27 \\
\hline & Colour removal & 0.04 & & 0.06 & 0.15 & 0.22 & 0.01 \\
\hline & Concentration & 0.00 & 0.06 & & 0.50 & 0.50 & 0.50 \\
\hline & Dose & 0.08 & 0.15 & 0.50 & & 0.50 & 0.50 \\
\hline & $\mathrm{pH}$ & 0.38 & 0.22 & 0.50 & 0.50 & & 0.50 \\
\hline & Time & 0.27 & 0.02 & 0.50 & 0.50 & 0.50 & \\
\hline
\end{tabular}


to coefficient values of $b_{1}, b_{2}, b_{5}$ and $b_{10}$ were statistically significant. The coefficient of determination $\left(R^{2}\right)$ for COD removal was 0.97 and the adjusted $R^{2}$ was 0.91 , which were indicators of the goodness of fit of the model. This depicted that $97 \%$ of the variation in COD removal was explained by the regression model.

The $p$ values for significant model terms in Table 7 are between 0.02 and 0.05 and only these terms were used in new regression and incorporated in Eq: 7 below:

$$
Y_{C O D}=29.28+11.14 X_{1}+5.60 X_{2}+6.79 X_{1} X_{2}+3.28 X_{3} X_{4}
$$

where: $\mathrm{Y}_{\mathrm{COD}}$ is the predicted value of COD removal (\%); and $X_{1}$ and $X_{2}$ are initial COD concentration and adsorbent dose, respectively. $X_{1} X_{2}$ and $\mathrm{X}_{3} \mathrm{X}_{4}$ were the interaction effects of the initial COD concentration with adsorbent dose and $\mathrm{pH}$ with contact time. The sign of the coefficient of regression indicates the direction of the relation and the magnitude of the number shows the degree of influence on COD removal. Generally, variables with a positive coefficient value enhanced COD removal whereas those with negative coefficient values were inversely related to removal. The degree of impact on removal increased with increasing numerical value of the regression coefficient in both cases.

All coefficient values in the regression equation were positive, which shows the enhancement of COD removal. This indicates that COD removal increases as each value of the main and interaction effects increases. The degree of impact on COD removal was in the order of $X_{1}>X_{1} X_{2}>X_{2}$ $>X_{3} X_{4}$. The extent of COD removal was highly influenced by initial COD concentration. Increase in initial COD concentration over the range used increased the removal of COD from $23.2 \%$ to $61.6 \%$. Similarly, the interaction effect between initial COD concentration and adsorbent dose also dominated COD treatment. The predicted value of the COD was the function of the main effects $\left(X_{1}\right.$ and $\left.X_{2}\right)$ and the 2-way interactions $\left(X_{1} X_{2}\right.$ and $\left.X_{3} X_{4}\right)$ in the model equation.

\begin{tabular}{|c|c|c|c|c|c|}
\hline \multicolumn{6}{|c|}{$\begin{array}{c}\text { TABLE 7 } \\
\text { Regression and ANOVA analysis of COD treatment }\end{array}$} \\
\hline Coefficients & Coefficient value & SE coefficient & \multicolumn{2}{|c|}{ t stat } & $P$-value \\
\hline$b_{0}$ & 29.28 & 1.166899 & \multicolumn{2}{|c|}{25.09} & 0.000 \\
\hline$b_{1}$ & 11.14 & 1.166899 & \multicolumn{2}{|c|}{9.54} & $0.000^{*}$ \\
\hline$b_{2}$ & 5.60 & 1.166899 & \multicolumn{2}{|c|}{4.80} & $0.005^{\star}$ \\
\hline$b_{3}$ & 1.29 & 1.166899 & \multicolumn{2}{|c|}{1.10} & 0.320 \\
\hline$b_{4}$ & 2.61 & 1.166899 & \multicolumn{2}{|c|}{2.24} & 0.075 \\
\hline$b_{5}$ & 6.79 & 1.166899 & \multicolumn{2}{|c|}{5.82} & $0.002^{*}$ \\
\hline$b_{6}$ & 2.60 & 1.166899 & \multicolumn{2}{|c|}{2.23} & 0.076 \\
\hline$b_{7}$ & -0.60 & 1.166899 & \multicolumn{2}{|c|}{-0.51} & 0.631 \\
\hline$b_{8}$ & 0.71 & 1.166899 & \multicolumn{2}{|c|}{0.61} & 0.570 \\
\hline$b_{9}$ & 0.32 & 1.166899 & \multicolumn{2}{|c|}{0.27} & 0.797 \\
\hline$b_{10}$ & 3.28 & 1.166899 & \multicolumn{2}{|c|}{2.81} & $0.039^{*}$ \\
\hline & DF & SS & FS & $F$ & Significant $F$ \\
\hline Regression & 10 & 3656.244 & 365.6244 & 16.78219 & 0.003073 \\
\hline Residual & 5 & 108.9322 & 21.78645 & & \\
\hline Total & 15 & 3765.176 & & & \\
\hline
\end{tabular}

Statistically significant $p$ values are designated by $\left({ }^{*}\right)$ in the table

\begin{tabular}{|l|c|c|c|c|c|}
\hline \multicolumn{7}{|c|}{ TABLE 8 } \\
\hline Coefficients & Coefficients value & Standard error & t Stat & $P$-value & \\
\hline$b_{0}$ & 37.83 & 2.40074 & 15.76 & $0.000^{*}$ & \\
\hline$b_{1}$ & 8.53 & 2.40074 & 3.55 & $0.016^{*}$ & \\
\hline$b_{2}$ & 5.98 & 2.40074 & 2.49 & 0.055 & \\
\hline$b_{3}$ & -4.45 & 2.40074 & -1.85 & 0.123 & \\
\hline$b_{4}$ & 11.71 & 2.40074 & 4.88 & $0.005^{\star}$ & \\
\hline$b_{5}$ & 1.40 & 2.40074 & 0.58 & 0.584 & \\
\hline$b_{6}$ & 6.98 & 2.40074 & 2.91 & $0.033^{\star}$ & \\
\hline$b_{7}$ & 3.13 & 2.40074 & 1.31 & 0.249 & \\
\hline$b_{8}$ & -2.13 & 2.40074 & -0.89 & 0.415 & \\
\hline$b_{9}$ & -6.98 & 2.40074 & -2.91 & $0.033^{*}$ & \\
\hline$b_{10}$ & -7.14 & 2.40074 & -2.97 & $0.031^{\star}$ & \\
\hline & DF & SS & FS & F & Significant F \\
\hline Regression & 10 & 6884.522 & 688.45 & 7.47 & 0.0193 \\
\hline Residual & 5 & 461.08 & 92.22 & & \\
\hline
\end{tabular}


For the colour treatment analysis, the coefficient of determination $\left(R^{2}\right)$ was 0.94 and the adjusted $R^{2}$ was 0.81 , which revealed that the model fits the experimental data well, though less so than the COD model. It was concluded that $94 \%$ of the variation in colour removal was explained by the model. Statistically significant terms (Table 8 ) were used to predict colour removal percentages which are given below.

$$
\begin{aligned}
Y_{\text {colour }}= & 37.83+8.53 X_{1}+11.71 X_{4}+6.98 X_{1} X_{3} \\
& -6.98 X_{2} X_{4}-7.14 X_{3} X_{4}
\end{aligned}
$$

where: $Y_{\text {colour }}$ is the predicted value of colour removal (\%) and $X_{1}, X_{4}$ the initial COD concentration and adsorbent dose, respectively. $X_{1} X_{3}, X_{2} X_{4}$ and $X_{3} X_{4}$ were the interactions between initial COD concentration and $\mathrm{pH}$, adsorbent dose and contact time, and $\mathrm{pH}$ and contact time, respectively.

All main and interaction effects had positive impacts on colour removal except the interaction between adsorbent dose and contact time, and $\mathrm{pH}$ and contact time. The positive values of coefficient terms enhanced the removal of colour and the negative values suppressed colour removal. The degree of impact on colour removal was in the order of $X_{4}>X_{1}>X_{3} X_{4}>X_{1} X_{3}$ $>X_{2} X_{4}$. Moreover, the dominant role for colour removal was played by contact time, followed by initial COD concentration.

\section{CONCLUSION}

Simultaneous removal of colour and COD from a melanoidin solution was effectively achieved by batch adsorption using chemically activated BFA. The adsorptive capacity $\left(q_{0}\right)$ was determined to be $124.80 \mathrm{mg} / \mathrm{g}$. BFA is a carbon-rich industrial waste and a good precursor for activated carbon. Characterization of BFA shows that the developed adsorbent was heterogeneous and had irregularly shaped pores, which were responsible for the uptake of different sizes of adsorbate in the adsorption process. In adsorption treatment, adsorbent surface area is important. Accordingly, a surface area of BFA of $160.9 \pm 2.8 \mathrm{~m}^{2} / \mathrm{g}$ was found to have the capacity to remove pollutants from ethanol distillery wastewater, particularly colour and COD components. Equilibrium isothermal studies showed that the Freundlich model better fitted the experimental data. With the help of a full factorial experimental design, maximum removal of COD was $61.6 \%$ at the optimum condition of adsorbent dose $4 \mathrm{~g}$, contact time $4 \mathrm{~h}, \mathrm{pH} 8$ and initial COD concentration $6000 \mathrm{mg} / \mathrm{L}$, whereas colour removal was $64 \%$ under the same conditions but at $\mathrm{pH}$ 3. The difference in efficiency of COD and colour removal is probably due to variable responses of colour and COD to independent factors. Furthermore, only a few components in the solution might be the cause of colour formation whereas any oxidizeable components will contribute to COD.

\section{ACKNOWLEDGMENTS}

We would like to thank the Ethiopian Institute of Water Resources, Addis Ababa University, for supervising financial support given by the United States Agency for International Development (USAID) under the USAID/HED grant in the Africa-US Higher Education Initiative - HED 052-9740-ETH11-01. We would also like to thank Ghent University, Faculty of Bioscience Engineering for offering us complete laboratory facilities, and Ethiopian Sugar Corporation Research Center for providing us bagasse fly ash and all other necessary support.

\section{REFERENCES}

ACHARYA BK, MOHANA S and MADAMWAR D (2008) Anaerobic treatment of distillery spent wash - A study on up flow anaerobic fixed film bioreactor. Bioresour. Technol. 99 (11) 4621-4626. https://doi.org/10.1016/j.biortech.2007.06.060

ARIMI MM, YONGJUN Z, GESINE G, KIRIMI K and SVEN-UWE G (2014) Antimicrobial colorants in molasses distillery wastewater and their removal technologies. Int. Biodeterior. Biodegrad. 87 34-43. https://doi.org/10.1016/j.ibiod.2013.11.002

ARIMI MM, ZHANGA Y, GÖTZA G and GEIßENA S (2015)

Treatment of melanoidin wastewater by anaerobic digestion and coagulation. Environ. Technol. 36 (19) 2410-2418. https://doi.org/10 $.1080 / 09593330.2015 .1032366$

ALOTHMAN Z, HABILA M and ALI R (2011) Preparation of activated carbon using the copyrolysis of agricultural and municipal solid wastes at a low carbonization temperature. Carbon 24 67-72.

APHA (American Public Health Association) (1998) Standard Methods for the Examination of Water and Wastewater $\left(20^{\text {th }}\right.$ edn $)$. American Public Health Association), American Water Works Association, Water Environment Federation, Washington, D.C. $541 \mathrm{pp}$.

BERNARDO EC, EGASHIRA R and KAWASAKI J (1997) Decolourization of molasses' wastewater using activated carbon prepared from cane bagasse. Carbon 35 (9) 1217-1221. https://doi. org/10.1016/S0008-6223(97)00105-X

BRERETON RG (2003) Chemometrics: Data analysis for the laboratory and chemical plant. Wiley, Chichester. 489 pp. https://doi. org/10.1002/0470863242

CHANDRA VS, DEO IM and MAN IS (2007) Adsorption thermodynamics and isosteric heat of adsorption of toxic metal ions onto bagasse fly ash (BFA) and rice husk ash (RHA). Chem. Eng. J. 13 (1-3) 2267-278.

CHAPMAN JS (2003) Biocide resistance mechanisms. Int. Biodeterior. Biodegrad. 51 (2) 133-138. https://doi.org/10.1016/ S0964-8305(02)00097-5

CHOOYOK P, PUMIJUMNOG $\mathrm{N}$ and USSAWARUIIKULCHAI A (2013)The water footprint assessment of ethanol production from molasses in Kanchanaburi and Supanburi province of Thailand. APCBEE Procedia 5 283-287. https://doi.org/10.1016/j. apcbee.2013.05.049

DADA AO, OLALEKAN AP, OLATUNYA AM and DADA O (2012) Langmuir, Freundlich, Temkin and Dubinin - Radushkevich Isotherms studies of equilibrium sorption of $\mathrm{Zn}^{2+}$ unto phosphoric acid modified rice husk. IOSR J. Appl. Chem. 3 (1) 38-45.

DAHIYA J, SINGH D and NIGAM P (2001) Decolourization of synthetic and spent wash melanoidins using the white-rot fungus Phanerocha ete chrysosporium JAG-40. Bioresour. Technol. 78 (1) 95-98. https://doi.org/10.1016/S0960-8524(00)00119-X

DAVID C, ARIVAZHAGAN M and TUVAKARA F (2015) Decolourization of distillery spent wash effluent by electro oxidation (EC and EF) and Fenton processes: A comparative study. Ecotoxicol. Environ. Saf. 121 142-148. https://doi.org/10.1016/j. ecoenv.2015.04.038

DEOKAR SK, MANDAVGANE SA and KULKARNI BD (2016) Behaviour of biomass multicomponent ashes as adsorbents. Curr. Sci. 110 (2) 1-7. https://doi.org/10.18520/cs/v110/i2/180-186

DOLPHEN R and THIRAVETYAN P (2011) Adsorption of melanoidins by chitin nanofibers. Chem. Eng. J. 166 (3) 890-895. https://doi.org/10.1016/j.cej.2010.11.063

EL-SHERIF IY and FATHY NA (2013) Modification of adsorptive properties of bagasse fly ash for up taking cadmium from aqueous solution. Environ. Res. Eng. Manage. 64 (2) 19-28.

GHOSH A and SAHA PD (2015) Optimization of copper adsorption by chemically modified fly ash using response surface methodology modeling. Desalin. Water Treat. 49 218-226. https://doi.org/10.1080 /19443994.2012.719324

GOTTIPATI R and MISHRA S (2010) Process optimization of adsorption of $\mathrm{Cr}(\mathrm{VI})$ on activated carbons prepared from plant precursors by a two-level full factorial design. Chem. Eng. J. 160 (1) 99-107. https://doi.org/10.1016/j.cej.2010.03.015 
GUPTA VK, JAIN CK, ALI I, SHARMA M and SAINI VK (2003) Removal of cadmium and nickel from wastewater using bagasse fly ash-a sugar industry waste. Water Res. 37 (16) 4038-4044. https://doi.org/10.1016/S0043-1354(03)00292-6

GUPTA VK, JAIN CK, ALI I, CHANDRA S and AGARWAL S (2002) Removal of lindane and malathion from wastewater using bagasse fly ash - a sugar industry waste. Water Res. 36 (10) $2483-$ 2490. https://doi.org/10.1016/S0043-1354(01)00474-2

HAIR JR J F, ANDERSON RE, TATHAM RL and BLACK WC (1998) Multivariate Data Analysis ( $5^{\text {th }}$ edn). Macmillan, New York. 768 pp.

HEGAZY AK, ABDEL-GHANI NT and EL-CHAGHABY GA (2014) Adsorption of phenol onto activated carbon from Rhazya stricta:determination of the optimal experimental parameters using factorial design. Appl. Water Sci. 42 (6) 952-956.

HESAS RH, ARAMI-NIYA A, DAUD WMAW and SAHU JN (2013) Preparation and characterization of activated carbon from apple waste by microwave-assisted phosphoric acid activation: Application in methylene blue adsorption. Bioresources 8 (2) 2950-2966.

IGWE JC and ABIA AA (2007) Equilibrium sorption isotherm studies of $\mathrm{Cd}$ (II), $\mathrm{Pb}$ (II) and $\mathrm{Zn}$ (II) ions detoxification from waste water using unmodified and EDTA-modified maize husk. Electron. J. Biotechnol. 10 (4) 536-548.

KAZEMI N, TAVAKOLI O, SEIF S and NAHANGI M (2015) Highstrength distillery wastewater treatment using catalytic sub- and supercritical water. J. Supercrit. Fluids 97 74-80. https://doi. org/10.1016/j.supflu.2014.10.025

KUMAR A, PRASAD B and MISHRA IM (2014) Adsorption of acrylonitrile from aqueous solution using bagasse fly ash. J. Water Process Eng. 2 129-133. https://doi.org/10.1016/j.jwpe.2014.05.003

KRISHNA PRASAD R and SRIVASTAVA SN (2009) Sorption of distillery spent wash onto fly ash: Kinetics and mass transfer studies. Chem. Eng. J. 146 (1) 90-97. https://doi.org/10.1016/j.cej.2008.05.021

KUSHWAHA JP, SRIVASTAVA VC and MALL ID (2010) Treatment of dairy wastewater by commercial activated carbon and bagasse fly ash: Parametric kinetic and equilibrium modelling, disposal studies. Bioresour. Technol. 101 (10) 3474-3483. https://doi. org/10.1016/j.biortech.2010.01.002

LATA H GARG VK and GUPTA RK (2008) Adsorptive removal of basic dye by chemically activated Parthenium biomass: Equilibrium and kinetic modeling. Desalination 219 (1-3) 250-261. https://doi.org/10.1016/j.desal.2007.05.018

MALL ID, SRIVASTAVA VC, AGARWAL NK and MISHRA IM (2005) Adsorptive removal of malachite green dye from aqueous solution by bagasse fly ash and activated carbon-kinetic study and equilibrium isotherm analyses. Colloids Surf. A 264 (1-3) 17-28. https://doi.org/10.1016/j.colsurfa.2005.03.027

MADU CP and LAJIDE L (2013) Physicochemical characteristics of activated charcoal derived from melon seed husk. J. Chem. Pharm. Res. 5 (5) 94-98.

MALVERN INSTRUMENTS LTD. (2007) Mastersizer 2000 User Manual (2007). Malvern Instruments Ltd. Enigma Business Park, Grovewood Road, Malvern, Worcestershire WR14 1XZ, United Kingdom. 154 pp.

MAURICE SO (2012) Simultaneous adsorption and biodegradation of synthetic melanoidin. Afr. J. Biotechnol. 11 (22) 6083-6090.

MILNE TA, BRENNAN AH and GLENN BH (1990) Sourcebook for Methods of Analysis for Biomass and Biomass-Conversion Processes. National Technical Information Service, US Department of Commerce, Springfield VA 22161. 428 pp.
MOHANA S, DESAI C and MADAMWAR D (2007) Biodegradation and decolourization of anaerobically treated distillery spent wash by a novel bacterial consortium. Bioresour.Technol. 98 (2) 333-339. https://doi.org/10.1016/j.biortech.2005.12.024

MOHANA S, ACHARYA BK and MADAMWAR D (2009) Distillery spent wash: Treatment technologies and potential applications. J. Hazardous Mater. 163 12-25.

NAGDA GK and GHOLE VS (2009) Biosorption of Congo red by hydrogen peroxide treated tendu waste. Iran. J. Environ. Health. Sci. Eng. 6 (3) 195-200.

NAIK N JAGADEESH KS and NOOLVI MN (2010) Enhanced degradation of melanoidin and caramel in biomethanated distillery spent wash by microorganisms isolated from mangroves. Iran. J. Energ. Environ. 1 (4) 347-351.

NWABANNE JT and IGBOKWE P (2012) Application of response surface methodology for preparation of activated carbon from palmyra palm nut. New York Sci. J. 5 (9) 18-25.

PURNOMO HW, SALIM C and HINODE H (2012) Effect of the activation method on the properties and adsorption behavior of bagasse fly ash-based activated carbon. Fuel Process. Technol. 102 132-139. https://doi.org/10.1016/j.fuproc.2012.04.037

RUFIÁN-HENARES JA and MORALES FJ (2007) Functional properties of melanoidins: In vitro antioxidant, antimicrobial and antihypertensive activities. Food Res. Int. 40 (8) 995-1002. https://doi.org/10.1016/j.foodres.2007.05.002

SIMARATANAMONGKOL A and THIRAVETYAN P (2010) Decolourization of melanoidin by activated carbon obtained from bagasse bottom ash. J. Food Eng. 96 (1) 14-17. https://doi. org/10.1016/j.jfoodeng.2009.06.033

SRIVASTAVA VC, MALL ID and MISHRA IM (2005) Treatment of pulp and paper mill wastewaters with poly aluminum chloride and bagasse fly ash. Colloids Surf. A 260 (1-3) 17-28. https://doi. org/10.1016/j.colsurfa.2005.02.027

SRIVASTAVA VC, MALL ID and MISHRA IM (2006) Equilibrium modelling of single and AQUACROP binary adsorption of cadmium and nickel onto bagasse fly ash. Chem. Eng. J. 117 79-91. https://doi.org/10.1016/j.cej.2005.11.021

TEZCAN UU, ATES F, ERGINEL N, OZCAN O and ODUNCU E (2015) Adsorption of Disperse Orange 30 dye onto activated carbon derived from holm oak (Quercus ilex) acorns: A $3^{\mathrm{k}}$ factorial design and analysis. J. Environ. Manage. 155 89-96. https://doi. org/10.1016/j.jenvman.2015.03.004

VAN HULLE SWH and CIOCCI MC (2012) Statistical evaluation and comparison of the chemical quality of bottled water and Flemish tap water. Desalination Water Treat. 40 (1-3) 183-193. https://doi. org/10.1080/19443994.2012.671166

WANG H, QIAN H and YAO W (2011) Melanoidins produced by the Maillard reaction: Structure and biological activity. Food Chem. 128 (3) 573-584. https://doi.org/10.1016/j.foodchem.2011.03.075

YADAV S, CHANDRA R and RAI V (2011) Characterization of potential MnP producing bacteria and its metabolic products during decolourization of synthetic melanoidins due to biostimulatory effect of d-xylose at stationary phase. Process Biochem. 46 (9) 1774-1784. https://doi.org/10.1016/j. procbio.2011.05.026 